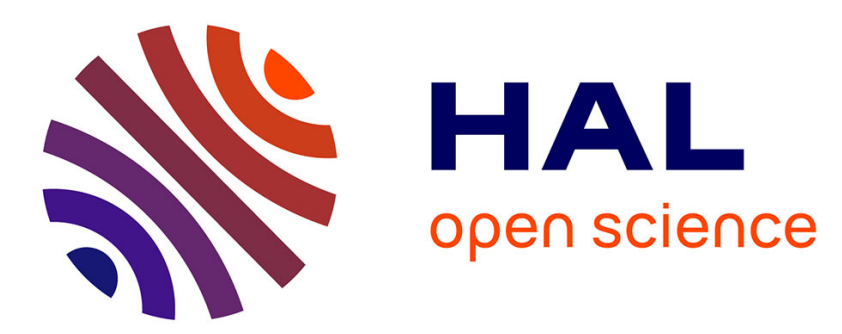

\title{
InAIN/GaN HEMT technology for robust HF receivers: An overview of the HF and LF noise performances
}

Séraphin Dieudonné Nsele, Jean-Guy Tartarin, Laurent Escotte, S Piotrowicz, S Delage

\section{- To cite this version:}

Séraphin Dieudonné Nsele, Jean-Guy Tartarin, Laurent Escotte, S Piotrowicz, S Delage. InAlN/GaN HEMT technology for robust HF receivers: An overview of the HF and LF noise performances. International Conference on Noise and Fluctuations, Jun 2015, X'IAN, China. 10.1109/ICNF.2015.7288538 . hal-01234023

\section{HAL Id: hal-01234023 \\ https://hal.science/hal-01234023}

Submitted on 26 Nov 2015

HAL is a multi-disciplinary open access archive for the deposit and dissemination of scientific research documents, whether they are published or not. The documents may come from teaching and research institutions in France or abroad, or from public or private research centers.
L'archive ouverte pluridisciplinaire HAL, est destinée au dépôt et à la diffusion de documents scientifiques de niveau recherche, publiés ou non, émanant des établissements d'enseignement et de recherche français ou étrangers, des laboratoires publics ou privés. 


\section{InAlN/GaN HEMT Technology for Robust HF Receivers: an Overview of the HF and LF Noise Performances}

\author{
S.D. Nsele, J.G. Tartarin, L. Escotte \\ LAAS-CNRS and University of Toulouse (UPS) \\ F-31031, Toulouse, France \\ tartarin@laas.fr
}

\author{
S. Piotrowicz, S. Delage \\ III-V Laboratory \\ 91460, Marcoussis, France
}

\begin{abstract}
From the first developments of Nitride technologies using $\mathrm{AlGaN} / \mathrm{GaN}$ heterostructures for designing high power, high frequency HEMT devices, we now assist to the emergence of new declination with InAIN/GaN heterostructures. Considering the expected better interface quality of this last technology as a consequence of the better lattice match, and better electrical properties, these HEMT devices attract much interest for high frequency applications (transmitter for power, receiver for low noise and robustness versus jamming). Different InAIN/GaN technological developments have been studied considering their frequency and noise parameters for low noise amplifiers in Ka-band. The paper addresses two issues related to noise in InAIN/GaN HEMT devices; one concerns the study of the HF noise performance for different technological processes and for the optimized technology, whereas the second focuses on the gate and drain current LFN spectra of competing technological versions featuring good HF dynamic and noise performance.
\end{abstract}

Keywords-Low Frequency Noise, High Frequency Noise, X and $\mathrm{K}$ band, InAlN/GaN HEMT

\section{INTRODUCTION}

Nitride technologies have registered a rapid growth during the last decade, especially on high power and high frequency segment markets. However, they are still far from exploiting their full potential. If $\mathrm{AlGaN} / \mathrm{GaN}$ technologies are ready for market, they are regularly improving their reliability figures of merit (pushing the junction temperature and the mean time to failure for high power applications). One of the reasons why AlGaN/GaN devices need strong efforts concerns the electrothermo-mechanical interactions that generate defects hampering to reach the ultimate potential of these technologies. An alternative has been found by using InAlN/GaN heterostructure featuring almost $18 \%$ of indium, which content is relevant with lattice match of the two materials. Moreover, the higher mobility and sheet density in the 2DEG is convenient for high power and high frequency applications. This work is part of the Genghis Khan project from the French National Agency for Research; the objective is to develop this technology for HF applications, through the design of a Kaband transceivers. Part of the project, besides the technological issues, concerns the declination of an optimized low noise process for robust HF receivers: this paper addresses two aspects of the noise studies through the analysis of HF and LF noise parameters. The first section presents the studies dedicated to high frequency noise on different technological processes, to find out the optimum declinations of the technologies for high frequency low noise applications. The second paragraph proposes investigations on low frequency noise for the selected technologies to detect some potential weaknesses of the transistor (traps), and to identify its technological maturity (1/f noise level).

\section{High FREQUENCY NOISE PARAMETERS}

HF noise parameters are measured using different subbands for an overall possible frequency range from $4 \mathrm{GHz}$ to $40 \mathrm{GHz}$. Devices under test have been characterized on 8 different processes featuring different gate length, gate width and gate-source gate-drain spacing, indium content between 18 and $21 \%$, with different doping concentrations and passivation types. Electrical small signal models have been developed, and frequency dispersion effects have been evidenced over a large frequency range, up to few $\mathrm{GHz}$; these rapid traps (or short term memory effects) impacting the $\mathrm{GHz}$ domain can strongly limit the performances of the devices for HF applications [1]. Medium and long term memory effects will also be evidenced in the section dedicated to LFN measurements. These trappingdetrapping HF mechanisms can also be illustrated in figure 1, where the minimum noise figure of merit $F_{\min }$ increases for decreasing frequencies below $8 \mathrm{GHz}$.

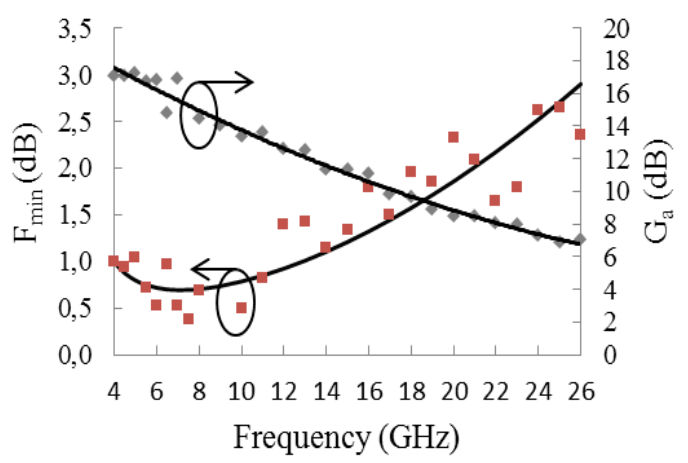

Fig. 1. Minimum noise figure $F_{\min }$ and Associated Gain $G_{a}$ versus frequency for an InAlN/GaN MOS-HEMT $\left(0.15 \times 2 \times 75 \mu m^{2}, V_{\mathrm{DS}}=5 \mathrm{~V}\right.$ and $\left.\mathrm{V}_{\mathrm{GS}}=-1 \mathrm{~V}\right)$. 
This behavior has been observed by Danneville et al. on GaAs FETs [2], and was attributed to shot noise. Fast traps affecting the transconductance and output conductance signatures versus frequency (as revealed for our devices), here combined with shot noise could explain this trend on $\mathrm{F}_{\min }$. The device under test from figure 1 features a transition frequency $\mathrm{F}_{\mathrm{t}}=40 \mathrm{GHz}$ and a maximum oscillation frequency $\mathrm{F}_{\max }=70$ $\mathrm{GHz}$. The value of $\mathrm{F}_{\min }=1.8 \mathrm{~dB}$ at $20 \mathrm{GHz}$ (with associated gain $\mathrm{G}_{\mathrm{a}}=8.8 \mathrm{~dB}$ ) is still above that of AlGaN/GaN HEMT [3][4] or In An/AlN/GaN transistors [5], featuring noise figures close to $1 \mathrm{~dB}$ at $26 \mathrm{GHz}$ [5] or at $36 \mathrm{GHz}$ [4] due to their low $\mathrm{L}_{\mathrm{G}} \leq 0.1 \mu \mathrm{m}$. The reduction of the drain current largely affects the performances of $F_{\text {min }}$, as observed between HEMT and MOS-HEMT devices in figure 2. A reduction on $\mathrm{F}_{\min }$ from 3.1 $\mathrm{dB}$ (HEMT) to $1.2 \mathrm{~dB}$ (MOS-HEMT) is obtained for $0.7 \mu \mathrm{m}$ gate length devices, at $4 \mathrm{GHz}$.

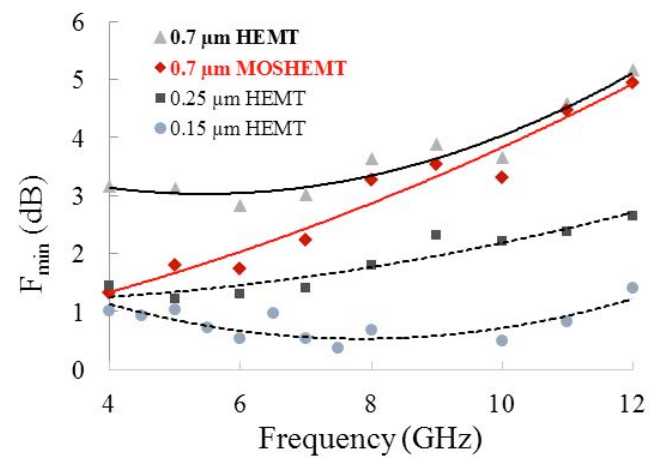

Fig. 2. Minimum noise figure $F_{\min }$ versus frequency for different InAlN/GaN HEMT and MOS-HEMT devices (measurements are given between 4-12 $\mathrm{GHz})$.

However, MOS-HEMT devices feature slightly lower $F_{t}$ and $\mathrm{F}_{\max }$, if compared with another competing technology with carbon doping (HEMT device featuring $\mathrm{F}_{\mathrm{t}}=55 \mathrm{GHz}$ and $\mathrm{F}_{\max }=135 \mathrm{GHz}$ ): these two technologies can be used to design a $30 \mathrm{GHz}$ LNA. Devices featuring $0.15 \mu \mathrm{m}$ or $0.25 \mu \mathrm{m}$ gate length have been studied for X-band and K-band applications. The optimum biasing point versus $\mathrm{V}_{\mathrm{GS}}$ (or $\mathrm{I}_{\mathrm{DSS}} / \mathrm{I}_{\mathrm{DS}}$ ) and $\mathrm{V}_{\mathrm{DS}}$ is mainly attributed to the elevated transconductance gain $g_{m}$ condition, to the reduction of diffusion noise at low $\mathrm{I}_{\mathrm{DS}}$ and to the management of self-heating effects under high dissipated power. An illustration of this optimum bias versus $V_{D S}$ is given in figure 3.

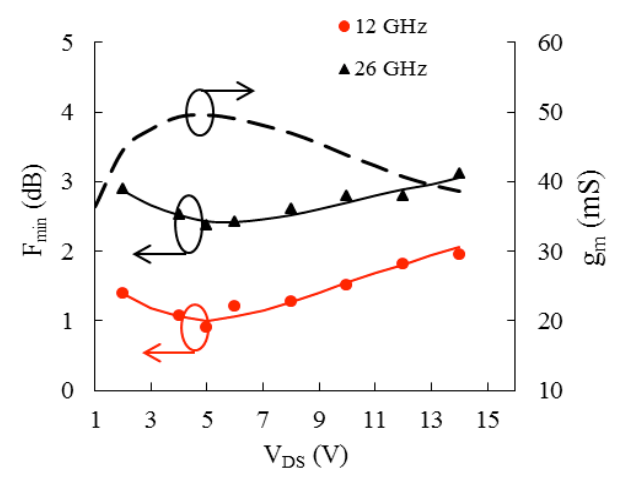

Fig. 3. Minimum noise figure $F_{\min }$ versus drain voltage $V_{D S}$ for frequencies of $12 \mathrm{GHz}$ and $26 \mathrm{GHz}$. Right axis represents the transconductance gain $\mathrm{g}_{\mathrm{m}}$.
$\mathrm{F}_{50}$ and four noise parameters measurements have been investigated and compared for X-band and Ka-band receiver's applications. $\mathrm{F}_{50}$ measurements are convenient for fast and systematic measurements as a first order analysis for biasing and sizing the device on each process declination, and also for a cross analysis between processes (with or without carbon doping, passivation type, indium content, gate length...). Then accurate characterization using the 4 noise parameters is performed $\left(\mathrm{F}_{\min }\right.$, equivalent noise resistance $\mathrm{R}_{\mathrm{n}}$ and complex optimum coefficient $\Gamma_{\text {opt }}$ ). Figure 3 presents the evolution of $\mathrm{F}_{50}$ versus $1 / \mathrm{L}_{\mathrm{G}}$ at $18 \mathrm{GHz}$, for devices from the 8 different wafers under test: devices are biased at the minimum noise conditions. The influence of the dynamic performances (through the reduction of $\mathrm{L}_{\mathrm{G}}$ ) is noticeable on noise improvement.

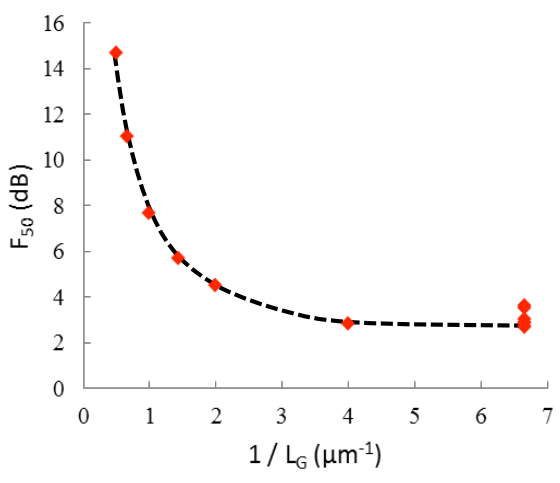

Fig. 4. $\mathrm{F}_{50}$ noise factor versus $1 / \mathrm{L}_{\mathrm{G}}$ : devices are biased at their optimum noise conditions (@18 GHz).

Figure 5 reports on the four noise parameters for a $0.15 \mu \mathrm{m}$ gate length device (plotted between 8-40 GHz). This device corresponds to the process and to the bias and size that will be implemented for the design of the robust LNA at $30 \mathrm{GHz}$, and presents a minimum noise figure of $F_{\min }=2 \mathrm{~dB}$ at $30 \mathrm{GHz}$.
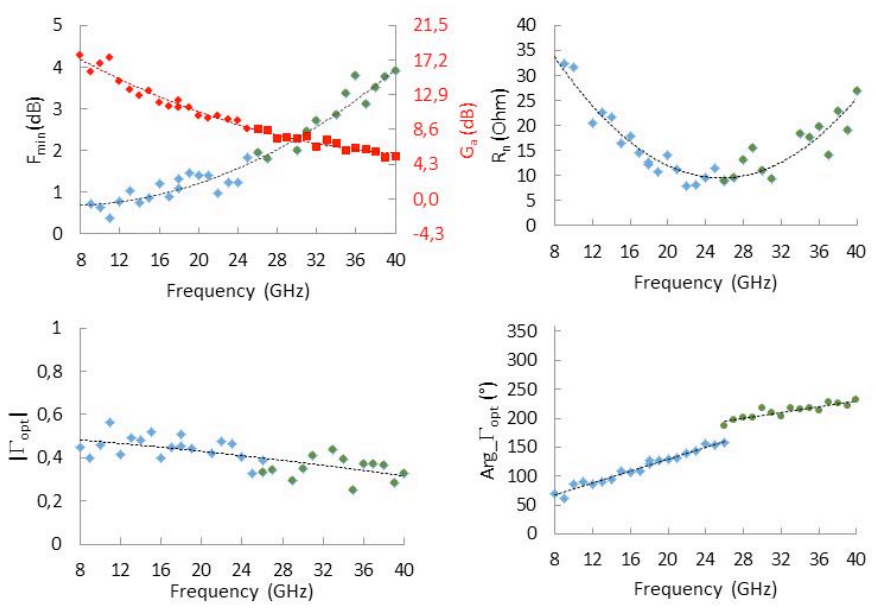

Fig. 5. Noise parameters $F_{\min }, R_{n}$ and $\Gamma_{\text {opt }}$ (magnitude and argument) and associated gain $G_{a}$ versus frequency $(8-40 \mathrm{GHz})$ for the selected device (MOS-HEMT device feat. $21 \%$ In content, $\mathrm{L}_{\mathrm{G}}=0.15 \mu \mathrm{m}, 2 \times 75 \mu \mathrm{m}$ gate width, $\mathrm{V}_{\mathrm{DS}}=6 \mathrm{~V}$ and $\left.\mathrm{I}_{\mathrm{DS}}=20 \mathrm{~mA}\right)$. 


\section{LOW FREQUENCY NOISE}

In this paper, Low Frequency Noise (LFN) is used as a diagnostic tool to assess the quality of the processed MOSHEMT evidencing the best HF performances from the previous study, and also on HEMT devices where Carbon has been used for doping. Gate and drain LFN current spectral density analysis of a transistor featuring $0.15 \mu \mathrm{m}$ of gate length are discussed. Measurements are performed between $1 \mathrm{~Hz}$ and $100 \mathrm{kHz}$, in two sub-bands for a better low frequency resolution. The two different processes that have been characterized feature almost the same characteristics in spite of differences (with or without carbon doping, passivation technique). The $\mathrm{S}_{\mathrm{IG}}$ spectra presents different generationrecombination centers (GR) superimposed with the $1 / \mathrm{f}$ flicker noise. Moreover, some Lorentzian contributions can be attributed to random telegraph signal (RTS) measured in time domain on these transistors [6]. A distributed model is used to account for the $1 / \mathrm{f}$ like behavior, based on the plot of $\mathrm{S}_{\mathrm{IG}} \times$ frequency versus frequency for an equally weighted extraction of the noise parameters. The contribution of the GR centers and of the distributed $1 / \mathrm{f}$ models are presented in figure 6 , as well as the total fit and measurement of $\mathrm{S}_{\mathrm{IG}}$.

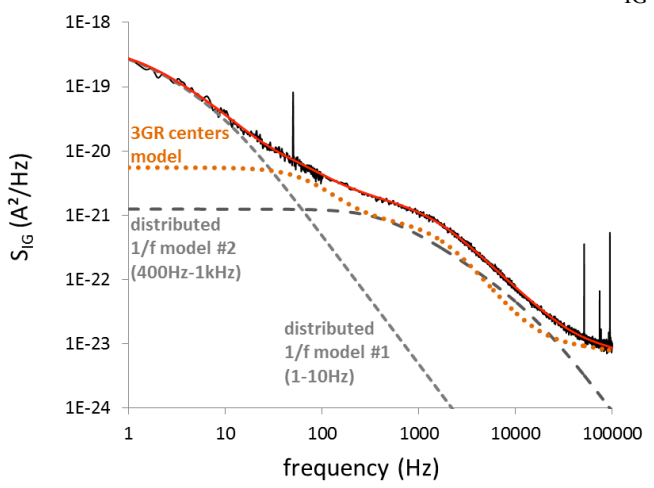

Fig. 6. Gate current spectral density $\mathrm{S}_{\mathrm{IG}}$ versus frequency (open drain, $\mathrm{V}_{\mathrm{GS}}=-$ $1 \mathrm{~V})$, and associated model based on 2 distributed $1 / \mathrm{f}$ models $(1-10 \mathrm{~Hz}$ and $400-1000 \mathrm{~Hz})[6]$ and $3 \mathrm{GR}$ centers $(80 \mathrm{~Hz}, 1.7 \mathrm{kHz}$, and above $200 \mathrm{kHz})$.

The evolution of the LFN spectra and of the fitting models is plotted in figure 7, for variable reverse $\mathrm{V}_{\mathrm{GS}}$ biasing (identified by $\mathrm{V}_{\mathrm{R}}$ ).

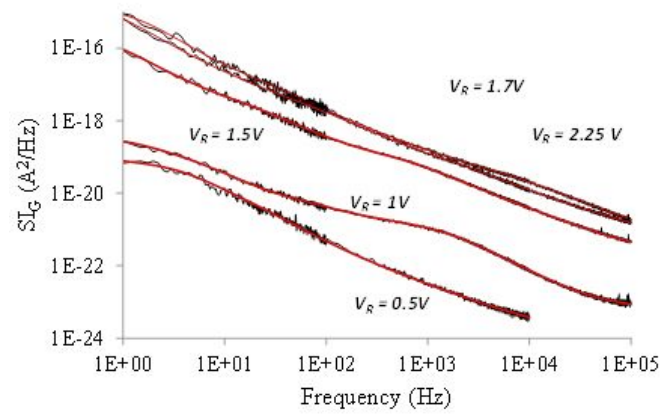

Fig. 7. Gate current spectral density $\mathrm{S}_{\mathrm{IG}}$ versus frequency (open drain), for variable reverse gate bias $V_{R}$.
Time constants attributed to GR centers are extracted between $1 \mu \mathrm{s}$ and $150 \mathrm{~ms}$. One GR center depends on the static bias voltage $\mathrm{V}_{\mathrm{GS}}$ (thermal conditions are stable when the drain is open); the logarithmic representation of its associated time constant evolves with the root square value of the electrical field according to Poole-Frenkel effect (the electrical field is extracted from a model using $\mathrm{C}-\mathrm{V}$ measurements). Moreover, figure 8 plots the evolution of $\mathrm{S}_{\mathrm{IG}} \times$ frequency versus $\mathrm{I}_{\mathrm{GS}}$ for three different frequencies. This plot features a linear model $\mathrm{S}_{\mathrm{IG}} \approx \mathrm{I}_{\mathrm{GS}}$, with $\alpha=3.3$ or $\alpha=1.5$ respectively for low and high levels of $\mathrm{I}_{\mathrm{GS}}$, and for different frequencies (10 $\mathrm{Hz}, 1 \mathrm{kHz}, 100 \mathrm{kHz}$ ). This normalized representation establishes quite the same behavior versus $\mathrm{I}_{\mathrm{GS}}$.

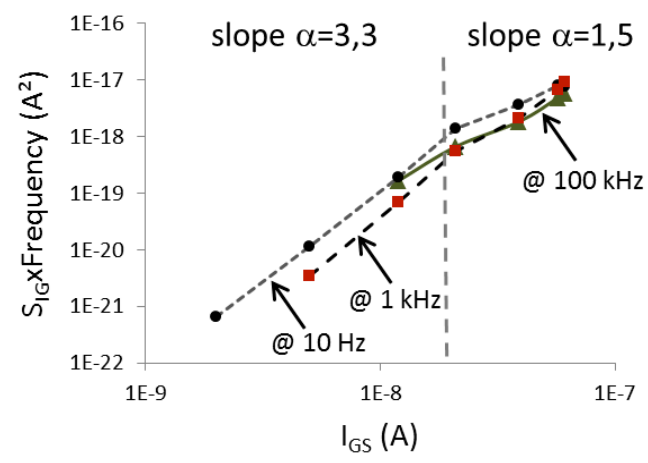

Fig. 8. $\mathrm{S}_{\mathrm{IG}} \times$ frequency versus $\mathrm{I}_{\mathrm{GS}}$ (at $1 \mathrm{~Hz}, 1 \mathrm{kHz}, 100 \mathrm{kHz}$ ).

The different $\alpha$ values are attributed to different leakage mechanisms at low and high reverse $\mathrm{V}_{\mathrm{GS}}$. Electrical modelling of $\mathrm{I}_{\mathrm{GS}}\left(\mathrm{V}_{\mathrm{GS}}\right)$ has evidenced different contributions to the reverse leakage current, with essentially Poole-Frenkel contribution before $\mathrm{V}_{\mathrm{R}}=1 \mathrm{~V}$ (i.e. $\mathrm{I}_{\mathrm{GS}}$ below $30 \mathrm{nA}$, as delimited in figure 8), and Fowler-Nordheim for higher reverse values of $V_{R}$ (so for gate currents $I_{G S}>30 n A$ ). This weight of each Poole-Frenkel or Fowler-Nordheim effect is correlated to the change in the slope on figure 8 . The $\alpha=1.5$ value is close to already published results on AlGaN/GaN HEMT [7]. As $\mathrm{S}_{\mathrm{IG}}$ spectra evidence numerous GR centers, the slope of $\alpha=3.3$ can be the consequence of these trapping-detrapping processes as stated previously by the time constant dependence with the root square of the electrical field for currents below $30 \mathrm{nA}$ (Poole-Frenkel contribution): indeed these GR centers are more pronounced at low $V_{R}$ in figure 7 (i.e. low $I_{G S}$ in figure 8 ) and trap-assisted mechanisms can be associated with this $\alpha=3.3$ value.

Noise spectral densities have also been measured on the drain access, when the gate is short circuited. Figure 9 presents the variation of the normalized spectra $\mathrm{S}_{\mathrm{ID}} / \mathrm{I}_{\mathrm{D}}$ when the gate voltage changes from open channel to pinch-off conditions. Only HEMT devices with carbon doping are presented and discussed for the drain current LFN measurements; indeed, these devices feature a non-monotonic atypical behavior of $S_{I D}$ plot versus $I_{D S}$ as shown in figure 10 . 


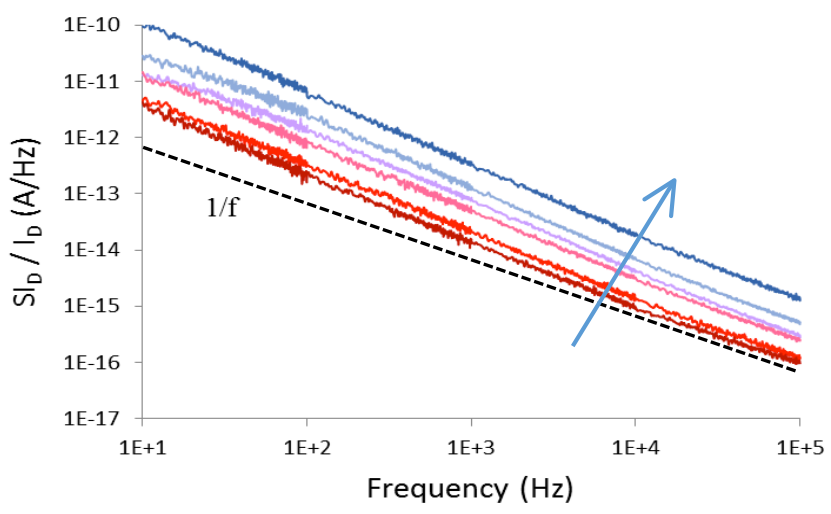

Fig. 9. Drain current spectral density $S_{I D}$ versus frequency (gate short circuited), for variable $\mathrm{V}_{\mathrm{GS}}\left(@ \mathrm{~V}_{\mathrm{DS}}=6 \mathrm{~V}\right)$.

Generally, $\mathrm{S}_{\mathrm{ID}}$ features an increase with $\mathrm{I}_{\mathrm{DS}}$, but for the device under test, a maximum is reached between pinch-off and open bias conditions in figure 10 (at $\mathrm{V}_{\mathrm{GS}}=-1.5 \mathrm{~V}$, i.e. $\mathrm{I}_{\mathrm{DS}}=35 \mathrm{~mA}$ ). As a large number of GR centers have been found to be located at the InAlN/GaN interface, we suppose that the action of the gate bias on the conduction band can be the cause of this inflexion on $\mathrm{S}_{\mathrm{ID}}$. The maximum on $\mathrm{S}_{\mathrm{ID}}$ also corresponds to the bias point where $g_{m}$ is at its maximum, but even considering the carrier number fluctuation (and surface density of slow trap centers) the spectral density should not decrease. We formulate the next hypothesis for this decrease of $S_{I D}$ when $\mathrm{V}_{\mathrm{GS}}$ increases from $\mathrm{V}_{\text {th }}$ to $0 \mathrm{~V}$. The conduction energy band bends towards the GaN layer when $\mathrm{V}_{\mathrm{GS}}$ increases; then the carriers are more distributed in the 2DEG volume, and less at the InAlN/GaN interface where traps are located. This is also convenient with the monotonic decrease of $\mathrm{S}_{\mathrm{ID}} / \mathrm{I}_{\mathrm{D}}$ when the gate voltage $\mathrm{V}_{\mathrm{GS}}$ shifts from $\mathrm{V}_{\text {th }}$ towards $0 \mathrm{~V}$. When $\mathrm{V}_{\mathrm{GS}}$ is near the pinch-off conditions, the conduction energy band confines the electrons close to this interface, and the normalized $\mathrm{S}_{\mathrm{ID}} / \mathrm{I}_{\mathrm{D}}$ noise density is maximum.

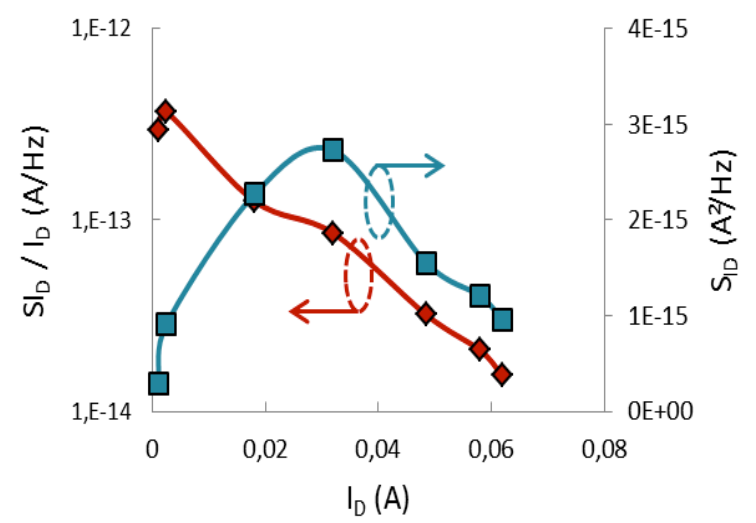

Fig. 10. Drain current spectral density $S_{I D}$ and $S_{I D} / I_{D}$ versus $I_{D S}(@ 1$ kHz, and for $\mathrm{V}_{\mathrm{DS}}=6 \mathrm{~V}$ ).

Charges at the interface between InAlN/GaN are evidenced by $\mathrm{S}_{\mathrm{ID}}$ and $\mathrm{S}_{\mathrm{ID}} / \mathrm{I}_{\mathrm{D}}$ behaviors versus the biasing conditions of the device under test, as well as trapping effects on $\mathrm{S}_{\mathrm{IG}}$, with largely distributed effects [1].

\section{CONCLUSION}

Wide bandgap InAlN/GaN MOS-HEMT and HEMT devices have been investigated in this paper: High frequency noise and Low Frequency Noise measurements have been performed on different technological processes. HF noise has been used to determine the optimum process for the design of a low noise amplifier in Ka-band: the effects of sizing, biasing and process variations (passivation types, doping levels) have been pointed out. $F_{\min }=1.9 \mathrm{~dB}$ have been measured at $30 \mathrm{GHz}$ on MOS-HEMT devices. Low frequency noise performances have evidenced numerous GR centers on the gate current spectral density, some attributed to RTS noise. Moreover, the evolution of the drain current spectral density does present a maximum value versus $I_{D S}$, instead of a monotonic increase as expected, and as usually found in the literature. The bending of the conduction energy band with the gate-source voltage could explain a redistribution of the carriers more in the $2 \mathrm{DEG}$, and less at the InAlN/GaN interface where traps have been localized. This is convenient with the behavior of the normalized $\mathrm{S}_{\mathrm{ID}} / \mathrm{I}_{\mathrm{D}}$ which decreases with increasing $\mathrm{I}_{\mathrm{DS}}$.

\section{ACKNOWLEDGMENT}

This work was supported by the Genghis Khan Project in the Framework of the French Research National Agency. The authors also acknowledge all the other partners of the project (Thales Communication, EGIDE, United Monolithic Semiconductors and Institut Lavoisier) for fruitful exchanges and discussion.

\section{REFERENCES}

[1] S. Nsele, L. Escotte, J.G. Tartarin, S. Piotrowicz, S.Delage. "BroadBand Frequency Dispersion Modeling of the Output Conductance and Transconductance in AlInN/GaN HEMTs", IEEE Transactions on Electron Devices, April 2013, Vol. 60 , , pp.1372-1378

[2] F. Danneville, G. Dambrine, H. Happy, P. Tadyszak, A. Cappy, "Influence of the gate leakage current on the noise performance of MESFETs and MODFETs," Solid-State Electronics, vol. 38, no. 5, pp. 1081-1087, 1995.

[3] L. P. Smorchkova, M. Wojtowicz, R. Tsai, R. Sandhu, M. Barsky, C. Namba, P.H. Liu, R. Dia, M. Truong, D. Ko, J. Wang, H. Wang, and A. Khan, "AlGaN/GaN HEMT high-power and low-noise performance at $f$ $\geq 20 \mathrm{GHz}$," in Proc. IEEE Lester Eastman Conf. on High Performance Devices, pp. 422-427, 2002.

[4] F. Medjoub, T. Tagro, M. Zegaoui, B. Grimbert, F. Danneville, D. Ducatteau, N. Rolland, P. A. Rolland, "Sub 1-dB minimum-noise-figure performance of GaN-on-Si transistors up to $40 \mathrm{GHz}$," IEEE Electron Device Letters, vol. 33, no. 9, pp. 1258-1260, 2012.

[5] P. Saunier, M. L. Schuette, T.-M. Chou, H.-Q. Tserng, A. Ketterson, E. Beam, M. Pilla, X. Gao, "InAlN barrier scaled devices for very high fT and low-voltage RF applications, " IEEE Trans. Electron Devices, vol. 60, no. 10, pp. 3099-3104, 2013.

[6] S. Nsele, L. Escotte, J.G. Tartarin, S. Piotrowicz, S.Delage. "Lowfrequency noise in reverse-biased Schottky barriers on InAlN/AlN/GaN heterostructures", Applied Physics Letters, Vol.105, N¹9, 192105p., Novembre 2014.

[7] J. G. Tartarin, S. Karboyan, D. Carisetti, B. Lambert, "Gate defects in AlGaN/GaN HEMTs revealed by low frequency noise measurement," International Conference on Noise and Fluctuations (ICNF) on IEEE, 2013 . 